\title{
A narrativa ficcional e a representação dos fatos políticos na telenovela
}

\section{Carla Montuori Fernandes}

\section{Resumo}

A relação entre mídia televisiva e política possui uma longa trajetória de pesquisa na área de comunicação. No âmbito da teledramaturgia, sua importância é potencializada pelo papel que o gênero exerce na discussão de temas e eventos políticos em diferentes momentos da história do país. Em meados de 2013, um ano antes das eleições presidenciais, a Rede Globo de Televisão levou ao ar o remake da telenovela Saramandaia para retratar temas políticos, com a trama principal voltada para corrupção e ineficácia governamental. Conferida a importância marcante da telenovela na sociedade brasileira, a pesquisa tem por objetivo analisar como foi construída a representação da política na nova edição da telenovela.

\section{Palavras-Chave}

Telenovela. Comunicação Política. Cultura.

\section{Carla Montuori Fernandes}

I carla_montuori@ig.com.br

Doutora e Pós-doutora em Ciências Sociais pela Pontifícia Universidade Católica de São Paulo (PUC-SP). É docente do Programa de Pós-Graduação em Comunicação e Cultura das Mídias da Universidade Paulista (UNIP) e da UNIFAI (Centro Universitário Assunção). Atua como pesquisadora do Núcleo de Estudos em Arte, Mídia e Política da PUC-SP.

\section{Introdução}

"Em um mundo onde o que não é transmitido pela TV não existe, um governo sem imagem tem toda razão para se inquietar" (DEBRAY, 1994, p. 95). Este, certamente, foi um dos primeiros efeitos da mídia televisiva a revolucionar o campo político. Desde seu surgimento oficial, em 1939, nos Estados Unidos, a televisão suplantou o rádio e a mídia impressa, devido à sua capacidade de atrelar códigos sonoros e imagéticos, o que atribuiu a esse meio de comunicação um poder fascinante. Essa sintonia entre a fala, o som, mas, principalmente, a imagem promove uma ação hipnótica sobre 0 telespectador, que, conforme atesta Guilherme Jorge Rezende (2000, p. 31), "já é suficiente para mantê-lo preso horas diante do televisor".

Além de se apoiar no caráter imagético, o poderio que a televisão detém no Brasil tem registro na sua própria dinâmica de instauração, que se caracterizou por funcionar, desde a fase inicial, como moeda de troca com o campo polític ${ }^{1}$ para cooptação de poder simbólico. Na obra Mídia e modernidade, Thompson (1998) relacionou 
quatro tipos de poder que são mediados pelos meios de comunicação: econômico, político, coercitivo e simbólico. 0 poder simbólico aparece na obra do autor como uma espécie de poder associado à capacidade de intervir no curso dos acontecimentos, de influenciar ações e crenças de outros e também como a possibilidade de criar acontecimentos mediante a produção e a transmissão de formas simbólicas.

No campo político, o poder simbólico assumido pela mídia revolucionou o ambiente eleitoral, ao propagar novas formas de mediação entre partidos, eleitores e candidatos. A notória visibilidade do candidato na mídia, efeito das inúmeras estratégias de marketing político, deslocou da cena pública a imagem do personagem e do partido para a esfera da política estetizada. ${ }^{2}$ Ao refletir sobre os mecanismos de profissionalização, separação e tecnocratização, Martín-Barbero (2000) alerta para a crise que 0 setor político enfrenta, sobretudo, durante 0 período eleitoral.

0 espetáculo midiático, além de oscilar de acordo com as intempéries da televisão, é também reflexo da própria encenação política, que, ao privilegiar mais a forma que o conteúdo, o meio sobre a mensagem, acaba por esvaziar o discurso, transformando 0 candidato em produto e 0 eleitor em mero consumidor, conforme elucidou o autor: "Se governa ou se faz oposição de cara para a câmera ou para as pesquisas, que são outra forma da indispensável e permanente produção de imagem" (MARTÍN-BARBERO, 2000).

Ao abordar a visibilidade que a mídia proporciona aos personagens políticos, Ianni (2000) utiliza a metáfora da obra $O$ príncipe, de Maquiavel, e aponta que parte da virtú e da fortuna, imprescindíveis para o sucesso do estadista no exercício do poder, são atributos do Príncipe Eletrônico, construído pela mídia, mais precisamente a televisão. A televisão é, para 0 autor, 0 veículo que melhor arquiteta 0 espaço de representação da política, funcionando como ágora eletrônica, local em que todos os indivíduos isolados e anônimos podem se reunir sem o risco de violência e engajar-se em debates e troca de informações. Diferentemente da ágora ${ }^{3}$ ateniense, representação física e social relacionada à ideia do aberto, a ágora eletrônica é alheia à ideia, à experiência do convívio e do debate em espaços públicos, circulando em um clima de simulacro da realidade, que só a mídia é capaz de reproduzir pelo domínio da linguagem (MARTÍN-BARBERO, 2001).

Ao retornar dos estúdios da NBC, nos Estados Unidos, em 1947, Assis Chateaubriand identificou na televisão um forte instrumento de poder político e resolveu implantá-Io no Brasil. É dele a frase: "Os nossos inimigos que se preparem: se só com rádios e jornais os Associados já tiram o sono deles, imaginem quando tivermos na mão um instrumento mágico como a televisão". (MORAIS, 2000, p. 39)

0 termo foi criado por Muniz Sodré (2006) ao refletir sobre a mediatização da política e sua espetacularização, ao desviar os personagens políticos da prática representativa concreta, para a performance imagética. 
Na mediação dos indivíduos com a esfera política, a mídia assumiu o papel antes relegado aos partidos e tornou-se substituta de algumas de suas funções tradicionais, como a fiscalização e 0 fornecimento de informações das ações governamentais, nas diversas instâncias de poder. Sartori (2001) criou o termo videopolítica para retratar como se processam as representações da política na televisão. 0 autor defende que a televisão tem modificado a natureza do homem ao alterar a capacidade cognitiva do indivíduo e transformar o Homo sapiens, fruto de uma cultura escrita, em Homo videns, produto da imagem. Desta forma, o poder da televisão surge da imagem, já que o olho acredita naquilo que vê e faz com que a autoridade cognitiva se torne a realidade vista (SARTORI, 2001).

No campo da representação política, o autor corrobora com a tese de que a diminuição da influência partidária, como máquina organizativa e canalizadora do voto popular, abre espaço para que a televisão invada a vida dos homens e exerça 0 papel de agente de representação e construção da cena política. É na busca da melhor imagem que a televisão se torna uma máquina de representação da realidade, e 0 critério de seleção de qualquer notícia fica subjugado aos entraves do próprio meio.

0 pensamento de Bourdieu (1997) assemelha-se ao de Sartori (2001), ao reconhecer que a imagem televisiva tem efeito real e, assim, ela pode fazer ver e fazer crer no que se faz ver. Ao utilizar a prática do ocultar mostrando, a televisão mostra algo diferente do que seria necessário apresentar, caso fizesse 0 que supostamente deveria fazer, isto é, informar. Ao fazer com que o público enxergue o mundo a partir de suas lentes e vieses, ou, como bem enfatizou Bourdieu (1997), o poder da mídia em fazer ver um fato pela sua ótica transforma qualquer acontecimento em um simulacro da realidade. Em seus estudos, Sodré oferece uma definição concisa de simulacro, apreendendo, também, a própria relação da televisão:

Como a imagem de Narciso no espelho, o simu-
lacro é inicialmente um duplo ou uma duplicação
do real. A imagem no espelho pode ser o reflexo
de um certo grau de identidade do real, pode en-
cobrir ou deformar essa realidade, mas também
pode abolir qualquer ideia de identidade, na me-
dida em que não se refira mais a nenhuma rea-
lidade externa, mas a si mesmo, ao seu próprio
jogo simulador. (SODRÉ, 1994, p. 28)

Nesse cenário, a mídia, em especial, a televisão, terminou por se constituir ator importante das mudanças políticas, sendo protagonista das novas maneiras de fazer política. Lima (2001) valoriza sua atuação ao lembrar que é, sobretudo, por meio da televisão que a política é construída simbolicamente e adquire significado. Em períodos eleitorais, os candidatos orientam-se cada vez mais por acontecimentos midiáticos, agendados pela televisão, em detrimento dos eventos genuínos da ação política.

Ágora era a praça principal da polis, a cidade grega da Antiguidade Clássica. 0 termo refere-se à praça pública, espaço onde se debatiam os problemas de interesse comum dos cidadãos atenienses. 
No Brasil, inúmeros autores investigaram de que maneira a televisão se torna um agente importante na constituição do cenário político durante os períodos eleitorais, com destaque para a representação da política nas telenovelas em Porto (1995 e 2002), Conti (1999), Hamburger (2003), Weber e Souza (2009), entre muitos outros.

A presença da telenovela como narrativa que ajuda a construir e disseminar imagens sobre a nação e a política nacional foi discutida por Hamburger (2005), na obra O Brasil antenado: a sociedade da telenovela, com base em análise da composição discursiva de fatos cotidianos da vida política nos anos de 1970, 1980 e 1990. Apoiada na falta de distinção entre ficção e realidade, a telenovela, relata a autora, colaborou para a consolidação de um imaginário político, sobretudo em cenários de disputas eleitorais.

0 poder da telenovela está no aprimoramento e no estreitamento entre ficção e realidade, associados à evolução pedagógica de programas que privilegiam conteúdos com registros didáticos, fazendo com que a programação adquira maior verossimilhança, credibilidade e legitimidade e promova uma "leitura documentarizante, capaz de tratar todo filme como documento" (ODIN apud LOPES, 2009, p. 37). Na esfera da produção, Motter (2004) identifica a existência de dois níveis constitutivos da telenovela brasileira: 0 melodramático e o realista. Essa dicotomia, que se apoia em enredos melodramáticos, românticos e sentimentais, alternados entre 0 sério e 0 cômico, ao lado de uma trama realista, constituída pela estrutura do cotidiano, com temáticas retiradas na dinâmica da vida social, explica em parte 0 sucesso da telenovela.

Atingindo grande êxito na sociedade brasileira, a telenovela se constitui como uma das principais fontes do imaginário social, pois, ao se sustentar em argumentos da vida cotidiana, acaba por ter importância na representação dos temas políticos. Martín-Barbero (2001) elucida que nenhum outro gênero de programação conseguiu ser tão popular na América Latina como a telenovela. A explicação reside no fato de 0 melodrama, segundo o autor, carregar em seu enredo as constituições e os sentimentos em que se constrói 0 imaginário coletivo.

Dada a importância marcante da telenovela na sociedade brasileira, faz-se necessário indagar como se constrói a representação de sentido da política nas narrativas ficcionais. Para ampliar 0 universo de pesquisas que estudam a política na teledramaturgia, 0 artigo tem por objetivo analisar como os acontecimentos de extensa visibilidade, envolvendo a esfera da corrupção política no Brasil, foram representados no remake da telenovela Saramandaia.

A escolha do objeto de pesquisa está relacionada à elevada audiência das telenovelas da Rede Globo, ${ }^{4}$ associada à longa trajetória da emissora na representação dos temas cotidianos, em especial do universo político. 0 referencial teórico 
norteador da pesquisa são os Estudos Culturais Latino-Americanos. A análise do enredo da telenovela se apoiará na tipologia desenvolvida por Weber e Souza (2009), por se aproximar de um modelo capaz de desvelar os modos peculiares com que a teledramaturgia aborda os temas políticos.

\section{A representação da política na telenovela}

Os conceitos de representação social se expandem por vários campos dos saberes, como psicologia, semiótica e antropologia, e adquirem fundamental importância nos estudos de comunicação. A tarefa de descrever como determinados grupos são representados é fundamentada por Stuart Hall (1997), teórico do campo da Comunicação, em um entrelaçamento com o imaginário social. Definida por Hall como parte fundamental do processo por meio do qual os sentidos são produzidos e trocados pelos membros de uma cultura, a representação envolve 0 uso da linguagem, de signos e de imagens que respondem por ou representam as coisas.

0 conceito de representação é considerado como parte essencial do processo de produção de significado por meio da linguagem e compartilhado entre membros de uma cultura. Adotando uma abordagem construcionista, Hall argumenta que a produção de sentido ocorre no interior da linguagem, por meio dos "signos, organizados em linguagens de diferentes tipos, para nos comunicarmos significativamente com os outros" (HALL, 1997, p. 17).

Soares (2007) acrescenta que a representação de sentido por meio da linguagem é produzida de forma intensa pelos meios de comunicação, uma vez que os produtos culturais produzidos pela mídia produzem imagens colhidas do mundo empírico para apresentá-las "na categoria de 'representantes' de pessoas, situações e fatos" (SOARES, 2007, p. 51).

As telenovelas, como produto da indústria cultural, são as que melhor reproduzem signos reconhecidos pelos sujeitos que, com certa frequência, se interessam e se identificam com o que é dito e realizado pelos personagens, ou mesmo que tais ações poderiam ocorrer no âmbito social.

Na esfera da representação política, Weber e Souza (2009) criaram uma tipologia de análise que se aproxima de um mapa capaz de revelar os modos peculiares com que a telenovela vem sendo retratada desde sua inauguração, de 1970 até 2008. Na esfera da produção narrativa, as autoras formulam três modalidades possíveis de inserção de temáticas políticas na dramatização. Na primeira modalidade, denominada "a política 
na trama ficcional", a política ocupa espaço central ou secundário na telenovela. Ao ocupar o espaço central no enredo, os eventos políticos acenam para questões como a restauração da ética, os desmandos do governo, o discurso da transformação social pela mudança política, os problemas econômicos, as disputas de poder e as lutas pela posse de terra. Já nas tramas secundárias, a menção à política ocorre para dar vida ao enredo, que se desenrola a partir de outra temática principal.

A segunda modalidade, nomeada como "citação estratégica da política", indica a presença esporádica, ou ocasional, da política na narrativa, por meio de citações propositais ou trechos de silenciamento, agendamento, intervenção e posicionamento, que, geralmente, estão presentes na trama secundária. Como exemplo, as autoras apontam os enredos que incorporam à vida de personagens secundários fatos da realidade próximos temporalmente dos acontecimentos narrados.

\section{A estratégia de silenciamento é caracterizada} pela omissão do tema na telenovela, sobretudo em momentos especiais da realidade política, aparentando que se pretende evitar críticas sobre determinadas circunstâncias ou concordância com fatos ocorridos. Essa estratégia pode ser identificada pela ausência do discurso ou da representação das eleições na teledramaturgia em momentos de disputas presidenciais, sem, entretanto, deixar de mencionar o nacionalismo no decorrer do enredo.
0 agendamento é identificado pela inserção de acontecimentos externos de grande repercussão nacional nas tramas secundárias, que se assemelham a fatos sociais, a questões políticas ou econômicas, cujo intuito parece ser o estímulo à crítica ou à concordância: "como se ocorresse uma imposição às tramas da telenovela" (WEBER e SOUZA, 2009, p. 156). A tática do agendamento também pode surgir no final das tramas, momento adequado para inserção de temas políticos que estão gerando polêmica nas instâncias públicas.

Conceituada por Weber e Souza (2009), a categoria intervenção corresponde à inserção de trechos dramáticos na narrativa, veiculados preferencialmente por meio de linguagens documentais, visando despertar reflexões e provocar ações no público. A estratégia nomeada de "merchandising social" pode abarcar citações que se originam de ações sociais, como movimentos organizados da sociedade civil e manifestações públicas, decisões externas produzidas pelo governo, como políticas públicas, temas políticos e de comportamento. No merchandising social e político, aponta Balogh (2005, p. 157) "0 ator e personagem se entrelaçam como porta-vozes privilegiados de problemas sociais e políticos mais prementes no momento da emissão dos programas".

A modalidade posicionamento se manifesta de duas formas: em situações e fatos políticos na teledramaturgia. Pode ser visível no âmbito da produção, ou seja, na dimensão extratextual da 
telenovela, especialmente quando envolve interesses comerciais e políticos das emissoras, ou por meio da inserção implícita de situações ocorridas na realidade política e encenadas de maneira verossímil nas tramas principais ou secundárias.

A terceira modalidade, nomeada de "repercussões informativas e mercadológicas da teledramaturgia", retrata o espaço em que ocorre a publicização da narrativa, fomentada por estratégias publicitárias e mercadológicas, com reportagens jornalísticas e peças publicitárias que proliferam em diversos veículos de comunicação, instigando a expectativa do telespectador dentro e fora da tela. Nesse sentido, a batalha travada pelos elevados indicadores de audiência leva ao desenvolvimento de estratégias extratextuais que pretendem estimular e prender o espectador, mantendo-o informado sobre 0 andamento da história e os momentos decisivos da trama, por meio de publicações em revistas, jornais, programas de televisão, redes sociais e demais mídias de relativa circulação. Acreditamos que essa tipologia, por se apoiar nos estudos culturais latino-americanos, fornecerá subsídios para a leitura dos objetos em questão.

\section{Entre a realidade e a ficção: uma análise da corrupção política em Saramandaia}

0 remake de Saramandaia foi veiculado no período de 24 de junho a 27 de setembro de 2013, um ano antes das eleições presidenciais de 2014. Inspirado na versão original de Dias Gomes, transmitida pela primeira vez em 1976, durante 0 período de rigorosa censura militar, a nova edição ganhou uma roupagem moderna e atualizada, como tramas e personagens reconhecidos na vida cotidiana, sem romper com 0 enredo original: 0 plebiscito para definir a mudança do nome da cidade de Bole-Bole para Saramandaia.

Na nova versão, produzida por Ricardo Linhares, a batalha se estabelece entre os progressistas, que defendem a adoção de Saramandaia, e os tradicionalistas, que lutam para que Bole-Bole não tenha seu nome alterado. A polêmica tem início quando 0 vereador João Gibão (Sergio Guizé) tem uma visão que lhe revela que tempos de paz e de mudanças políticas seriam alcançados se 0 nome da cidade fosse mudado para Saramandaia. Para colocar o sonho em prática, Gibão apresenta um projeto de lei e lidera o movimento de mudança.

0 enredo também é marcado pela briga de décadas entre as famílias Rosado e Vilar, que disputam 0 comando da cidade. A rivalidade entre as famílias foi motivo de morte para ambos os lados, mas é nutrida por histórias de amor que se estendem por três gerações. A matriarca da família Rosado, Candinha, interpretada por Fernanda Montenegro, viveu no passado uma intensa paixão por Tibério (Tarcísio Meira), coronel e patriarca da família Vilar, mas a família a obriga a se casar com outro homem. Mais tarde, o filho de Candinha, Zico Rosado (José Rosado), e a filha de Tibério, Vitória Vilar (Lilia Cabral), revivem a mesma paixão durante a juventude, mas se distanciam em razão 
de uma tragédia familiar, que faz aumentar o ódio entre as famílias.

Vitória Vilar parte de Bole-Bole grávida de Zico Rosado, deixando para trás a história de amor que viveu com o inimigo político da família, e une-se a outro homem, que assume a paternidade de Zélia (Leandra Leal). Trinta anos depois, com a morte do marido, Vitória Vilar volta a Bole-Bole com o filho mais novo, Pedro Vilar, interpretado por André Bankoff, que durante a trama desenvolve um romance secreto e proibido com a neta de Zico Rosado, Stela (Laura Neiva).

A disputa política entre as famílias já fica clara no primeiro capítulo, quando Vitória Vilar retorna à cidade e pousa com um helicóptero em plena praça, para apoiar a manifestação e a discussão política entre os que defendiam a permanência do nome Bole-Bole e o movimento que defendia a mudança para Saramandaia, do qual sua filha Zélia era a líder. Em meio a histórias de amor e ódio, a batalha familiar se trava entre o coronel Zico Rosado e a revolucionária Zélia Vilar, que desconhecem a verdade sobre a história da paternidade.

Para evitar que a alteração do nome da cidade afete a produção e a venda da cachaça BoleBole, produzida pela empresa do influente ex-prefeito Zico Rosado, práticas de corrupção e crimes ocupam 0 espaço central da narrativa. Nesse sentido, verifica-se que a disputa política e a corrupção têm 0 enredo voltado para a modalidade "a política na trama central". Apesar de 0 ambiente retratar uma cidade fictícia, 0 tempo da narrativa está próximo da atualidade e mostra os conchavos e as falcatruas políticas da atualidade. Na trama, a luta pela mudança política é refletida com frequência nas manifestações da juventude saramandista, as quais evocam 0 termo "mudancismo" como marca de um novo tempo.

A estreia do remake de Saramandaia, gravada meses antes da veiculação, tem início com a manifestação social dos jovens personagens, que percorrem as ruas de Bole-Bole, reivindicando novos direitos, carregando uma bandeira clara de repúdio à corrupção. É possível reconhecer na telenovela os escândalos políticos e as manifestações populares que atingiram as principais ruas do país em junho e julho de 2013. Coincidentemente, a primeira grande manifestação social que levou às ruas centenas de milhares de jovens brasileiros, na luta contra a corrupção e pela defesa dos direitos dos cidadãos, eclodiu dois dias antes do início da telenovela, em 22 de junho de 2013.

Com isso, nota-se que a estratégia de agendamento se incorpora à telenovela nos episódios posteriores, produzidos para obter sintonia com a realidade sociopolítica vivida pelo país, já que as manifestações sociais tornaramse frequentes na trama. Na batalha por angariar votos para o plebiscito, a personagem Zélia e 0 vereador João Gibão, líderes do movimento de mudança do nome da cidade, promovem manifestações em vários episódios da novela. 
Assim, percebe-se que 0 autor, Ricardo Linhares, investiu na estratégia de agendamento de temas que obtiveram grande repercussão nacional nas tramas secundárias de Saramandaia, conforme reafirma em entrevista ao jornal Folha de S.Paulo, ao dizer que aproveitou a liberdade que 0 horário proporciona para abordar determinados temas políticos e sociais que considera relevantes. Segundo o autor, "A dramaturgia não pode ser chapa-branca". Weber e Souza (2009, p. 156) apontam que a intenção do agendamento é buscar 0 efeito de estímulo à visão crítica ou à aprovação dos acontecimentos, como uma imposição às tramas na novela.

As práticas coronelistas são utilizadas pelo ex-prefeito Zico Rosado para obter vitória no plebiscito. A fim de tentar convencer a população de Bole-Bole a não alterar o nome da cidade, o braço-direito e afilhado do prefeito corrupto, Carlito (Marcos Pasquim), arma uma farsa para representar um falso milagre do Santo Dias, padroeiro da cidade, que pronuncia, por meio de microfones escondidos, as palavras Bole-Bole, Bole-Bole. Para legitimar o aparente milagre, Carlito fura o dedo com um alfinete e coloca uma gota de sangue no olho do santo. A encenação foi concretizada para não deixar dúvidas ao povo, se o santo chorou e pronunciou o nome Bole-Bole é porque o nome da cidade não deve ser alterado.

Nesse aspecto, a estratégia de posicionamento está visível na teledramaturgia, uma vez que a cena reproduz fenômenos da realidade política
(WEBER e SOUZA, 2009), realizando uma paródia das velhas oligarquias do nordeste brasileiro, habituadas a manipular a fé religiosa, fazendo crer que as mazelas e a seca da região não são resultado de políticas coronelistas que se beneficiam da ingenuidade e da miséria da população para se manter no poder, por meio da compra de votos, mas, sim, de uma maldição milenar que envolve santos e padroeiros.

Após a derrota nas eleições, na tentativa de aprovar um novo plebiscito para que a cidade volte a se chamar Bole-Bole, Zico Rosado propõe ao deputado Cazuza (Marcos Palmeira) que organize um esquema de "mesadão" para compra de votos dos vereadores na Câmara Municipal. A conversa sobre a prática de corrupção, denominada por Zico Rosado de "propinoduto", é filmada pelo deputado Cazuza com uma microcâmera escondida, aprovada pelo Ministério Público, que flagra detalhes do funcionamento da mesada.

0 dinheiro é empilhado por Zico Rosado, na mesa do seu escritório, em vários maços de notas de $\mathrm{R} \$ 100,00.0$ político ainda se dispõe a pagar mensalmente aos vereadores a mesma quantia para que Saramandaia volte a se chamar BoleBole. 0 farmacêutico Cazuza é orientado pelo político corrupto a guardar todo o dinheiro do mesadão nas meias, nos bolsos ou na cueca. Ao detalhar o esquema, Zico Rosado alerta que se a fraude for descoberta, ele alegará inocência e afirmará desconhecer a prática de suborno. 
Novamente a estratégia de agendamento é encenada ao fazer alusão aos escândalos do mensalão petista e ao propinoduto tucano. Pela assimilação de acontecimentos, personagens e discursos (WEBER e SOUZA, 2009), o enredo traz uma referência direta ao escândalo do mensalão, o qual eclodiu em 2005, no primeiro mandato do governo petista de Luiz Inácio Lula da Silva (20022006), que alegou desconhecer o esquema. 0 evento contou com o episódio em que o secretário de organização do Diretório Estadual do PT no Ceará, José Adalberto Vieira da Silva, que também atuava como assessor do irmão de José Genoíno (PT), foi flagrado pelos agentes da Polícia Federal, ao tentar embarcar para Fortaleza, com dólares ocultos na cueca, embrulhados em um saco plástico. Vieira da Silva afirmou à Polícia Federal que o montante era procedente da venda de legumes.

0 termo propinoduto, referenciado em Saramandaia como um esquema de corrupção proposto por Zico Rosado para compra de votos, também faz alusão à blindagem da gestão PSDB em São Paulo, envolvendo atos de corrupção para desvio de verba pública, com o fim de abastecer 0 caixa dos tucanos. A prática tucana, que recebeu novas denúncias de corrupção no mês de junho de 2013, remonta a uma ação criminosa, que ocorria nos governos tucanos de Mário Covas (PSDB), José Serra (PSDB) e Geraldo Alckmin (PSDB), desde 1998.

A prisão de Zico Rosado também incorpora uma temática política recorrente no Brasil. Acusado e condenado, o delegado Petronílio, interpretado por Theodoro Cochrane, ao conduzir o corrupto para a cadeia da cidade, local que conta apenas com um preso e onde as portas da prisão permanecem abertas, indica que fechará a cela de Rosado, por confiar mais em bandidos do que em políticos. Como representação da realidade política, Zico Rosado não fica encarcerado por muito tempo, consegue um habeas corpus e sai da prisão.

A modalidade posicionamento se manifesta de modo implícito no último capítulo de Saramandaia, tal qual mencionou Weber e Souza (2009), quando ocorre uma combinação entre fenômenos da realidade política atual e fenômenos de ficção. A telenovela evidencia os principais problemas sociais e políticos do país, com menções a práticas de corrupção, em alusão direta e total desqualificação dos políticos atuais. Em contraposição, no espaço ficcional, a restauração da ética e o tempo de mudança têm início com a vitória do plebiscito do grupo que defendia a troca de nome para Saramandaia. 0 nascimento de bebês com asas, no hospital de Serro Azul, cidade próxima da região, demarca, no discurso da juventude saramandista, 0 começo de uma geração cercada de mudanças, cuja marca principal é a liberdade.

Em total sintonia com o telespectador, o discurso final da telenovela, proferido pelos casais Gibão e Marcina, Zélia e Lua, estabelece uma analogia com as principais reivindicações populares do país, associando-as com o percurso para um novo tempo. A personagem Zélia esclarece que 
é tempo de muitas mudanças, não somente em Saramandaia, mas em todos os cantos. A metáfora do novo tempo aparece como frase na cena final do último capítulo, evocando que o tempo de mudança política está próximo.

\section{Considerações Finais}

Desde sua fase inaugural, na década de 1950, a telenovela, ainda que com caráter experimental, foi capaz de representar temas políticos e agendar pautas que se alinhavam aos principais debates do país. Ao atuar na linha tênue entre ficção e realidade, os conteúdos das telenovelas operam na produção de signos, por vezes retirados do mundo empírico, para representar e produzir reconhecimento junto ao telespectador.

0 remake da telenovela Saramandaia, inserida no plano do surrealismo fantástico, retratou, por meio de uma disputa entre famílias, temas políticos de intensa repercussão nacional, em vésperas da campanha presidencial de 2014. A coincidência que se instaurou entre os movimentos sociais que eclodiam nas ruas do país e o primeiro capítulo da trama, o qual se desenvolve mostrando um atrito entre os manifestantes que lutam por mudanças políticas na cidade de Bole-Bole, incentivou o autor Ricardo Linhares a investir pesadamente no tema.

Em vésperas de disputa eleitoral, os partidos que polarizam a disputa pela Presidência do Brasil, desde 1994, viram os principais desmandos dos seus mandatos representados na trama. 0 esquema de mesadão proposto pelo político corrupto Zico Rosado para compra de votos dos deputados, metáfora do escândalo do mensalão, articulado por membros do PT, enquanto o presidente Luiz Inácio Lula da Silva (2002-2006) exercia seu primeiro mandato, e 0 propinoduto do PSDB, cujas denúncias recaem nos governos tucanos de São Paulo e Minas Gerais, ecoaram no enredo.

Com o lema "É tempo de mudança", Saramandaia foi veiculada em total sincronia com a indignação que percorreu as ruas das grandes capitais do Brasil. A corrupção ativa do personagem Zico Rosado é extinta pelos frequentes manifestos para derrotar o político inescrupuloso no plebiscito para a troca do nome da cidade e pela intensa luta da juventude saramandista para desmascarar as inúmeras fraudes do ex-prefeito. No último capítulo, a telenovela se prevalece do tom poético das cenas finais e incorpora o discurso da mudança política na fala da personagem Zélia, líder do movimento saramandista, que aponta a possibilidade de construção de um novo cenário nacional pela união e luta da população.

\section{Referências}

BALOGH, Ana Maria. 0 discurso ficcional na TV - sedução e sonhos em doses homeopáticas. São Paulo: Edusp, 2002. . Conjunções - disjunções transmutações: da literatura ao cinema e à TV. $2^{\mathrm{a}}$ ed. São Paulo: Annablume, 2005. 
BOURDIEU, Pierre. Sobre a televisão. Rio de Janeiro: Jorge Zahar, 1997.

CONTI, Mario Sergio. Notícias do Planalto. A imprensa e o poder nos anos Collor. São Paulo: Companhia das Letras, 1999.

DEBRAY, Regis. 0 Estado sedutor: as revoluções midiológicas do poder. Petrópolis: Vozes, 1994.

HALL, Stuart. The work of representation. IN: HALL, Stuart (org.). Representation. Cultural representations and signifying practices. Sage; Open University: London; Thousand Oask; New Delhi, 1997.

HAMBURGER, Esther. 0 Brasil antenado: a sociedade da novela. Rio de Janeiro: Zahar, 2005. "Política e telenovela". In: BUCCI, Eugenio (Org.). A TV aos 50: criticando a televisão brasileira no seu cinquentenário. São Paulo: Perseu Abramo, 2003.

IANNI, Octávio. 0 príncipe eletrônico. In: DOWB0R, Ladislau et al. (Orgs.). Desafio da comunicação. Petrópolis: Vozes, 2000.

LIMA, Venício A. Mídia: teoria e política. São Paulo: Fundação Perseu Abramo, 2001.

LOPES, Maria Immacolata Vassalo de. Telenovela como recurso comunicativo. Matrizes, v. 3, p. 21-48, 2009. (USP. Impresso.)

MARTÍN-BARBER0, Jesus. 0 medo da mídia política, televisão e novos modelos de representação. In: DOWB0R, Ladislau et al. (Orgs.). Desafios da comunicação. Petrópolis: Vozes, 2000.

MARTÍN-BARBER0, Jesus; REY, German. 0s exercícios do ver: hegemonia audiovisual e ficção televisiva. São Paulo: Senac, 2001.

MORAIS, Fernando. Chatô, o rei do Brasil. São Paulo: Companhia das Letras, 2000.

MOTTER, Maria Lourdes. Mecanismos de renovação do gênero telenovela: empréstimos e doações. In: LOPES,
Maria Immacolata Vassalo de V. (Org.). Telenovela: internacionalização e interculturalidade. São Paulo: Loyola, 2004.

PORTO, Mauro. Telenovelas e política: o CR-P da eleição presidencial brasileira de 1994. Comunicação \& Política, v. 1, nº 3, abr.-jul. 1995. Telenovelas e controvérsias políticas: interpretações da audiência sobre Terra Nostra. Trabalho apresentado no XI Encontro Anual da Associação Nacional de Programas de Pós-Graduação em Comunicação (COMPÓS), Rio de Janeiro/RJ, 4-7 jun. 2002 .

REZENDE, Guilherme Jorge de. Telejornalismo no Brasil: um perfil editorial. São Paulo: Summus, 2000.

SARTORI, Giovanni. Homo videns: televisão e póspensamento. Bauru: Edusc, 2001.

SOARES, Murilo César. Representações da cultura mediática: para a crítica de um conceito primordial. Trabalho apresentado ao GT Cultura das Mídias. XVI Compós, UTP, Curitiba, 2007.

SODRÉ, Muniz. A máquina de Narciso: televisão, indivíduo e poder no Brasil. São Paulo: Cortez, 1994. . As estratégias sensíveis: afeto, mídia e política. Petrópolis: Vozes, 2006.

THOMPSON, John B. A mídia e a modernidade. Uma teoria social da mídia. Petrópolis: Vozes, 1998.

WEBER, Maria Helena. Imagem Pública. In: RUBIM, Antonio Albino Canelas (Org.). Comunicação e

Política: conceitos e abordagens. São Paulo: Editora UNESP, 2004.

WEBER, Maria Helena; SOUZA, Maria Carmem Jacob de. Dramatização da política na telenovela brasileira. In: GOMES, Itania Maria Mota. Televisão e Realidade. Bahia: EDUFBA, 2009. 
The fictional narrative and representation of political events in the soap opera

\section{La narración ficticia}

y la representación

de los acontecimientos

políticos en la novela

\section{Resumen}

La relación entre los medios de comunicación de televisión y la política tiene una larga historia de investigación en el área de la comunicación. Dentro de la serie de televisión, su importancia se ve reforzada por el papel activo que desempeña el género en el debate de las cuestiones y los acontecimientos políticos en los diferentes períodos de la historia. A mediados de 2013, un año antes de las elecciones presidenciales, la Red Globo de Televisión, salió al aire el remake de la novela Saramandaia describir temas políticos, con la trama principal que da a la corrupción y la ineficiencia gubernamental. Em función de la amplitud de la novela en la sociedad brasileña, la investigación tiene como objetivo analizar la forma en que se construyó la representación de la política en la nueva edición de la novela.

\section{Palabras-Clave}

Telenovela. Comunicación Política. Cultura. 


\section{Expediente}

A revista E-Compós é a publicação científica em formato eletrônico da Associação Nacional dos Programas de Pós-Graduação em Comunicação (Compós). Lançada em 2004, tem como principal finalidade difundir a produção acadêmica de pesquisadores da área de Comunicação, inseridos em instituições do Brasil e do exterior.

\section{E-COMPÓS I www.e-compos.org.br I E-ISSN 1808-2599}

Revista da Associação Nacional dos Programas

de Pós-Graduação em Comunicacão.

Brasília, v.17, n.3, set./dez. 2014

A identificação das edições, a partir de 2008

passa a ser volume anual com três números.

\section{CONSELHO EDITORIAL}

Afonso Albuquerque, Universidade Federal Fluminense, Brasil Alberto Carlos Augusto Klein, Universidade Estadual de Londrina, Brasil Alex Fernando Teixeira Primo, Universidade Federal do Rio Grande do Sul, Brasil Rio Grande do Sul, Brasi

Ana Gruszynski, Universidade Federal do Rio Grande do Sul, Brasil Ana Silvia Lopes Davi Médola, Universidade Estadual Paulista, Brasil André Luiz Martins Lemos, Universidade Federal da Bahia, Brasi Ângela Freire Prysthon, Universidade Federal de Pernambuco, Brasil Antônio Fausto Neto, Universidade do Vale do Rio dos Sinos, Brasil Antonio Carlos Hohlfeldt, Pontifícia Universidade Católica do Rio Grande do Sul, Brasil Antonio Roberto Chiachiri Filho, Faculdade Cásper Líbero, Brasi Arlindo Ribeiro Machado, Universidade de São Paulo, Brasil Arthur Autran Franco de Sá Neto, Universidade Federal de São Carlos, Brasil Benjamim Picado, Universidade Federal Fluminense, Brasil César Geraldo Guimarães, Universidade Federal de Minas Gerais, Brasil Cristiane Freitas Gutfreind, Pontifícia Universidade Católica do Rio Grande do Sul, Brasil Denilson Lopes, Universidade Federal do Rio de Janeiro, Brasil Denize Correa Araujo, Universidade Tuiuti do Paraná, Brasil Edilson Cazeloto, Universidade Paulista, Brasil

Eduardo Vicente, Universidade de São Paulo, Brasil

Eneus Trindade, Universidade de São Paulo, Brasil

Erick Felinto de Oliveira, Universidade do Estado do Rio de Janeiro, Brasil Florence Dravet, Universidade Católica de Brasilia, Brasil

Gelson Santana, Universidade Anhembi/Morumbi, Brasi Gilson Vieira Monteiro, Universidade Federal do Amazonas, Brasil Gislene da Silva, Universidade Federal de Santa Catarina, Brasil Guillermo Orozco Gómez, Universidad de Guadalajara, México Gustavo Daudt Fischer, Universidade do Vale do Rio dos Sinos, Brasil Hector Ospina, Universidad de Manizales, Colômbia Herom Vargas, Universidade Municipal de São Caetano do Sul, Brasil leda Tucherman, Universidade Federal do Rio de Janeiro, Brasil Inês Vitorino, Universidade Federal do Ceará, Brasil Janice Caiafa, Universidade Federal do Rio de Janeiro, Brasil Jay David Bolter, Georgia Institute of Technology, Estados Unidos Jeder Silveira Janotti Junior, Universidade Federal de Pernambuco, Brasi João Freire Filho, Universidade Federal do Rio de Janeiro, Brasil John DH Downing, University of Texas at Austin, Estados Unidos Ana Carolina Damboriarena Escosteguy, Pontifícia Universidade Católica do

José Afonso da Silva Junior, Universidade Federal de Pernambuco, Brasil José Carlos Rodrigues, Pontifícia Universidade Católica do Rio de Janeiro, Brasil José Luiz Aidar Prado, Pontifícia Universidade Católica de São Paulo, Brasil José Luiz Warren Jardim Gomes Braga, Universidade do Vale do Rio dos Sinos, Brasil Juremir Machado da Silva, Pontifícia Universidade Católica do Rio Grande do Sul, Brasil Laan Mendes Barros, Universidade Metodista de São Paulo, Brasi Lance Strate, Fordham University, USA, Estados Unidos Lorraine Leu, University of Bristol, Grã-Bretanha Lucia Leão, Pontifícia Universidade Católica de São Paulo, Brasil Luciana Panke, Universidade Federal do Paraná, Brasil Luiz Claudio Martino, Universidade de Brasília, Brasil Malena Segura Contrera, Universidade Paulista, Brasil Márcio de Vasconcellos Serelle, Pontifícia Universidade Católica de Minas Gerais, Brasil Maria Aparecida Baccega, Universidade de São Paulo e Escola Superior de Propaganda e Marketing, Brasi Maria das Graças Pinto Coelho, Universidade Federal do Rio Grande do Norte, Brasil Maria Immacolata Vassallo de Lopes, Universidade de São Paulo, Brasil Maria Luiza Martins de Mendonça, Universidade Federal de Goiás, Brasil Mauro de Souza Ventura, Universidade Estadual Paulista, Brasil Mauro Pereira Porto, Tulane University, Estados Unidos Nilda Aparecida Jacks, Universidade Federal do Rio Grande do Sul, Brasil Paulo Roberto Gibaldi Vaz, Universidade Federal do Rio de Janeiro, Brasil Potiguara Mendes Silveira Jr, Universidade Federal de Juiz de Fora, Brasil Renato Cordeiro Gomes, Pontifícia Universidade Católica do Rio de Janeiro, Brasil Robert K Logan, University of Toronto, Canadá

Ronaldo George Helal, Universidade do Estado do Rio de Janeiro, Brasil Rosana de Lima Soares, Universidade de São Paulo, Brasi Rose Melo Rocha, Escola Superior de Propaganda e Marketing, Brasil Rossana Reguillo, Instituto de Estudos Superiores do Ocidente, México Rousiley Celi Moreira Maia, Universidade Federal de Minas Gerais, Brasi Sebastião Carlos de Morais Squirra, Universidade Metodista de São Paulo, Brasil Sebastião Guilherme Albano da Costa, Universidade Federal do Rio Grande do Norte, Brasil

Simone Maria Andrade Pereira de Sá, Universidade Federal Fluminense, Brasi Suzete Venturelli, Universidade de Brasília, Brasil

Tiago Quiroga Fausto Neto, Universidade de Brasília, Brasil

Valerio Fuenzalida Fernández, Puc-Chile, Chile

Veneza Mayora Ronsini, Universidade Federal de Santa Maria, Brasi Vera Regina Veiga França, Universidade Federal de Minas Gerais, Brasil

\section{COMISSÃO EDITORIAL}

Cristiane Freitas Gutfreind I Pontifícia Universidade Católica do Rio Grande do Sul, Brasil Irene Machado I Universidade de São Paulo, Brasil

Jorge Cardoso Filho I Universidade Federal do Recôncavo da Bahia, Brasil Universidade Federal da Bahia, Brasil

CONSULTORES AD HOC

Adriana Amaral, Universidade do Vale do Rio dos Sinos, Brasil

Alexandre Rocha da Silva, Universidade Federal do Rio Grande do Sul, Brasi

Arthur Ituassu, Pontifícia Universidade Católica do Rio de Janeiro, Brasil

Bruno Souza Leal, Universidade Federal de Minas Gerais, Brasil

Elizabeth Bastos Duarte, Universidade Federal de Santa Maria, Brasil

Francisco Paulo Jamil Marques, Universidade Federal do Ceará, Brasi

Maurício Lissovsky, Universidade Federal do Rio de Janeiro, Brasil

Suzana Kilpp, Universidade do Vale do Rio dos Sinos, Brasil

Vander Casaqui, Escola Superior de Propaganda e Marketing, Brasi

EDIÇ̃̃O DE TEXTO E RESUMOS I Press Revisão

SECRETÁRIA EXECUTIVA I Helena Stigger

EDITORAÇÃo ELETRÔNICA I Roka Estúdio
COMPÓS I www.compos.org.br

Associação Nacional dos Programas de Pós-Graduação em Comunicação

Presidente

Eduardo Morettin

Universidade de São Paulo, Brasil

eduardomorettin@usp.br

Vice-presidente

Inês Vitorino

Universidade Federal do Ceará, Brasil

ines@ufc.br

Secretária-Geral

Gislene da Silva

Universidade Federal de Santa Catarina, Brasil

gislenedasilva@gmail.com 